\title{
¿Quién escucha a los terapeutas? Representaciones de los profesionales en un CAS de Cataluña
}

\author{
Carmen Laura Paz Reverol \\ Doctora en Antropología (URV) \\ Laboratorio de Antropología Social y Cultural (LASYC) \\ Universidad del Zulia (LUZ), Venezuela \\ cpaz@luz.edu.ve
}

Resumen: El punto de partida de esta investigación es el interés por describir y analizar las representaciones de los terapeutas y profesionales en un centro de atención para drogodependientes de una ciudad media de Cataluña. Nuestro objetivo se centra en analizar cómo los terapeutas identifican, denominan e interpretan la enfermedad en las personas con problemas de alcohol (pcpa) y cómo diseñan sus terapias y tratamientos desde el enfoque sistémicorelacional. Con este fin, se recogen las experiencias de 16 profesionales (médicos, psicólogos, psiquiatras, trabajadores sociales, enfermeros, mediadores interculturales) de dicho centro con las personas que acuden al servicio y sus narrativas en cuanto a la enfermedad y el tratamiento de los usuarios; también las reflexiones sobre la evolución y las perspectivas del Centro de Atención para Drogodependientes desde el punto de vista de los terapeutas como actores sociales. A partir de una metodología etnográfica centrada en el punto de vista del actor, la convivencia durante un año con los terapeutas ha permitido captar el sentido que adquiere para ellos la enfermedad y el tratamiento, circunscrito al ámbito biomédico. Como estrategias básicas para la recogida de información se utilizaron la observación participante y la entrevista en profundidad.

Palabras clave: alcobol, terapia sistémica-relacional, narrativas, terapeutas, tratamientos

Abstract: The aim of this research is to determine and analyse representations of therapists and professionals in a Drug Addict Attention Centre in a medium-size city in Catalonia. Our research analyses how therapists identify, name and interpret illness in persons who have alcohol problems and how they devise therapies and treatments from a systemic-rational

\footnotetext{
$\bar{*}$ Este artículo forma parte de una tesis doctoral culminada titulada Padecimientos y tratamientos en torno al alcohol: representaciones y prácticas, dirigida por el Dr. Oriol Romaní i Alfonso y presentada en la Universitat Rovira i Virgili en el año 2011.
} 
point of view. To this end, the researchers gathered the experiences of 16 professionals from the centre (psychologists, psychiatrists, social workers, nurses, intercultural mediators) and of the individuals who attend the health centre. The aim was to listen to their narratives and accounts regarding illness and the treatments provided to the patients, and also to determine the perceptions of the therapists and patients regarding the Drug Addict Attention Centre and its activities. By using an ethnographic methodology centred on the patients' impressions and sharing their experiences with the therapists over the course of one year, the researchers have been able to determine the meanings with which the biomedical field has circumscribed the patients' illnesses and treatments. Participant observation and in-depth interviews were the main strategies used for gathering information.

Keywords: alcohol, relational systematic therapy, narrative, therapists, treatments.

\section{Introducción}

Uno de los interrogantes que a menudo escuché entre los profesionales de la salud y terapeutas que atendían a las personas con problemas de alcobol y otras drogas era: ¿quién cuida al cuidador? La pregunta era muy sugerente, pues señalaba que nadie cuida de los profesionales de la salud que atienden casos de drogodependencias. Así pues, yo quería escuchar a los profesionales acerca del sujeto que trataban. Es así como la pregunta "¿quién cuida al cuidador?" se convierte en “¿quién escucha a los terapeutas?”. Sin ninguna duda yo quería escucharlos. De ahí el título de este artículo, que pone de manifiesto, por mi parte, la disposición para la escucha, y, por parte de los profesionales, la extrañeza y a la vez comodidad de ser escuchados por una antropóloga, pues señalaban que siempre debían escuchar a las personas que trataban, pero que casi nunca eran escuchados. En la formulación de esta pregunta es indudable la influencia de Bimbela Pedrola (1995), quien plantea la necesidad del cuidado de los profesionales de la salud. Uno de estos cuidados se plasmaría mediante la escucha de las inquietudes, los conocimientos y las experiencias del terapeuta acerca de su trabajo con personas que tienen problemas de drogodependencias. Con la pregunta también se plantea el papel de la antropología médica en estos escenarios para facilitar una relación de apoyo y escucha no solo del terapeuta, sino también del usuario.

Hay que distinguir esta interacción (investigadora-terapeutas) de las que comúnmente suelen tener los psicoterapeutas y que se basan en la "supervisión", 
que evoca "una relación jerárquica en la cual a los saberes de una de las partes se les atribuye un estatus de 'súper' visión y la otra parte es sometida a esta supervisión en temas referidos a su trabajo y a su identidad como terapeuta" (White, 2002:188). Por lo tanto, en la interacción entre la antropóloga y los profesionales de la salud estos podían expresar lo que quisieran sobre su identidad profesional, grupal o institucional y sobre los sujetos que atienden.

Es necesario destacar que la escucha de la etnógrafa a los terapeutas fue bien acogida desde el principio. Señalaba una de las profesionales con más an-

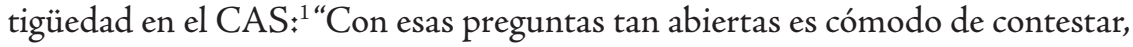
pues, porque permites expresar muchas cosas, divagar, hay otros que divagamos demasiado, otros no mucho" (doctora Batalla, ${ }^{2} 2009$ ). Surgieron actitudes de extrañeza, pero más de aceptación:

¿Quieres que te diga una cosa? Al principio me ha costado un poquito, la verdad. Como un esfuerzo que tenía que hacer, pero después me sentía tan a gusto hablando contigo, que sabes escuchar muy bien..., sí, eso es algo que te valoro, porque yo estoy acostumbrada a escuchar a los demás, pero no a que me escuchen a mí, eso me pasa tan pocas veces que me he sentido muy a gusto..., sabes escuchar y observar la realidad y eso es lo que hace un antropólogo, me parece. Luego supongo que tú haces tus hipótesis y tus elucubraciones [se ríe] (doctora Batalla, 2009).

A partir de la interacción investigadora-profesionales de la salud se puede afirmar que el intercambio ha sido simétrico, basado en el respeto mutuo y la confianza; en palabras de Good, es "una conversación, una danza, una búsqueda del significado..." (Good, 2003).

Los terapeutas se perciben a sí mismos como un grupo muy sólido y que se ha ganado el reconocimiento como un servicio de drogodependencias de referencia en Cataluña. En tal sentido, conversaron con la antropóloga acerca de su labor terapéutica y su experiencia con las personas que atienden. Esto nos permite hacer un paralelismo de su trabajo con la labor del sastre, pues una

1. Centro de Atención y Seguimiento de las Drogodependencias (CAS), en adelante CAS.

2. Los nombres que aparecen en esta investigación no se corresponden con los reales; ello se hizo con el objetivo de resguardar la confidencialidad y la protección de datos de carácter personal de los sujetos que participaron en la investigación. En el contexto español, de acuerdo con la Ley 15/1999, de 13 de diciembre, de Protección de Datos de Carácter Personal, los datos personales que se requieren (por ejemplo, edad, sexo o datos de salud) son los necesarios para cubrir los datos del estudio. Solo interesaron los datos de salud, edad, sexo y ocupación. 
de las primeras metáforas que surgen al observar a los profesionales es la idea de que representan un "traje a la medida" para las personas con problemas de drogas; este planteamiento evoca muchas imágenes que se tratarán de plasmar en el texto. Por medio de una metodología cualitativa que incluyó técnicas de recogida de información (entrevistas en profundidad, observación, observación participante), los profesionales que laboran con problemas de drogas hicieron un recorrido de sus años de servicio. En las entrevistas, los terapeutas rememoran sus vivencias y experiencias en el CAS. Se propone, a partir de Good (2003: 28), plasmar "una visión de la enfermedad como un «síndrome de experiencia», «un conjunto de palabras, experiencias y sentimientos que suelen concitarse respecto a los miembros de una sociedad»".

En consecuencia, nos interesamos por las representaciones que el personal sociosanitario elabora acerca de las personas con problemas de alcohol (pcpa), ${ }^{3}$ así como las representaciones sobre su rol terapéutico. Nos interesa conocer de qué manera se estructuran las representaciones de los terapeutas sobre el padecimiento de las personas con problemas de alcohol y otras drogas, signos y síntomas, tratamientos. Los objetivos que se persiguen son interpretar las representaciones de los terapeutas sobre el padecimiento y el tratamiento de la persona con problemas de drogas.

\section{Precisiones teóricas y metodológicas}

Para Geertz (1989), la antropología es un tipo de ciencia distinto de las ciencias experimentales y su diferencia se basa en la descripción y explicación.

Semejante concepción de la manera en que funciona la teoría en una ciencia interpretativa sugiere que la distinción (en todo caso relativa) que se da entre las ciencias experimentales o de observación entre "descripción" y "explicación", se da en nuestro caso como una descripción aún más relativa entre "inscripción” ("descripción densa”) y "especificación” ("diagnóstico") entre establecer la significación que determinadas acciones sociales tienen para sus actores y anunciar, lo más explícitamente que podamos, lo que el conocimiento así alcanzado muestra sobre la sociedad a la que se refiere y, más allá de ella, sobre la vida social como tal (Geertz, 1989: 36).

3. Se aborda la propuesta de Cunillera i Forns (2006), que es el concepto con el que se manejan los profesionales de la psicología desde el punto de vista más formal por considerar que no estigmatiza a las personas que consumen una determinada sustancia, en este caso el alcohol. 
Para este autor, la interpretación es una forma particular de descripción ya que considera que es la única forma de describir los hechos de significados.

Dar cuenta de las representaciones de los actores sociales que pertenecen a las instituciones médicas permite interpretar los conceptos - significados-y comportamientos (haceres) para tratar la enfermedad y el cuidado que requiere desde su propia perspectiva. La práctica médica será entendida entonces, según Parsons, como un "mecanismo" en el sistema social para afrontar las enfermedades de sus miembros. Implica una serie de roles institucionalizados. El rol de médico o profesional sociosanitario se enfoca a "cuidar de los enfermos". De esta manera, "el rol del médico se encuentra en un puesto avanzado en el continuum de los niveles cada vez más altos de competencia técnica exigidos para su desempeño" (Parsons, 1999: 406).

En las representaciones y prácticas de los profesionales de la salud se parte del supuesto de "que es irrelevante que al médico le guste o le disguste el enfermo concreto como persona; en la mayoría de los casos el problema puramente objetivo consiste en habérselas con una enfermedad particular" (Parsons, 1999: 407). Hay enfoques más actuales que no desmienten esta aseveración; White (2002: 156) señala que "el terapeuta es un observador informado, quien, en lo que al conocimiento se refiere, ha logrado un estatus autónomo, imparcial y desinteresado. La persona que hace la consulta es considerada el objeto de este conocimiento y, por medio de esta interacción, es constituida como el 'otro'”. De esta manera, los discursos profesionales refuerzan "poderosamente el dualismo sujeto/objeto tan generalizado en la estructuración de las relaciones en la cultura occidental" (White, 2002: 159). Existen muchas críticas a las pretensiones de verdad de estos discursos profesionales y a las relaciones de poder que reproducen; por ejemplo, es necesario distinguir cómo son percibidas las cosas en sí mismas y cómo pensamos que son, y hay cuestionamientos con respecto a la participación de los terapeutas en los procesos terapéuticos en condiciones de neutralidad e imparcialidad.

El trabajo etnográfico (método que marca la particularidad de la antropología) es el método privilegiado en esta investigación, en la cual se utilizaron principalmente como estrategias básicas para la recogida de información las entrevistas en profundidad y la observación participante. Se presenta un tipo de práctica de investigación que nos permite sacar el máximo provecho del enfoque holístico relacional, al analizar "los problemas globalmente, rela- 
cionándolos de manera contextuada en sus distintos niveles de la realidad y a través de distintas articulaciones entre dichos niveles". De igual manera, dicho enfoque supone "la dialéctica entre los niveles micro y macrosocial", que permite "describir y explicar de manera concreta las cosas, al mismo tiempo que de este análisis concreto podemos sacar hipótesis, reflexiones genéricas, verificar o contradecir teorías generales" (Romaní, 1999: 150).

Toda labor etnográfica requiere trabajo de campo, que es el proceso de observación, recolección, selección de la información, análisis e interpretación que se genera a partir de la interacción con los sujetos implicados. En este caso, la relación continua con los usuarios y profesionales de la salud del CAS aportó una buena información de cómo van cambiando los problemas vinculados a las drogodependencias (incluyendo el alcohol) en una zona determinada.

Se trata entonces de recuperar el punto de vista de estos actores sociales con la finalidad de "incluir el saber/poder local" y revalidar a unos actores sociales en la medida en que "pueden tener representaciones y prácticas similares, pero también saberes diferenciales, conflictivos y hasta antagónicos respecto, por ejemplo, de los procesos s/e/a" desde la perspectiva de la antropología médica (Menéndez, 2002).

En la construcción de los instrumentos y su aplicación se establecieron los siguientes criterios: la entrevista se estructuró para obtener inicialmente los datos de manera espontánea y se utilizaron preguntas abiertas para no condicionar las respuestas. Se considera, a partir de las ideas de Menéndez (1996: 65), que "las respuestas de los médicos constituyen, para nosotros, la expresión de un conjunto organizado a partir de la unidad donde trabajan, de la institución a la que pertenecen, del universo de pacientes comunes, del área de intervención y de la vinculación con otros grupos de profesionales".

También se asume, junto con Good (2003: 28), que el lenguaje de la medicina "es un rico lenguaje cultural, vinculado a una versión de la realidad y del sistema de relaciones sociales altamente especializada y, al aplicarse a la atención médica, confluye con profundas preocupaciones morales y con sus más obvias funciones técnicas". A partir de este lenguaje cultural se prestará atención a los significados y las interpretaciones de la enfermedad en el dispositivo de atención a las drogodependencias. En este texto se transcribirán y analizarán las representaciones que incorporan los términos según las definiciones 
de los terapeutas, funcionando nuestros conceptos como marco referencial de interpretación.

La etnografía se realizó en un período de trabajo de campo de un año en un centro de atención y seguimiento de las drogodependencias (CAS) de la provincia de Tarragona, España, en el cual se observó y entrevistó a dieciséis terapeutas - médicos (2), psiquiatras (2), psicólogos (4), enfermeros (3), educadoras sociales (2), trabajadores sociales (2) y mediadora intercultural (1) que laboran en ese centro y ofrecen servicio a una población abierta o asegurada residente en un área determinada que se caracteriza por pertenecer, en su mayoría, a niveles socioeconómicos medios-bajos.

\section{Descripción y análisis de los resultados}

Los resultados dan cuenta de las representaciones sobre la persona con problemas de alcohol, la enfermedad y el tratamiento. En este apartado se presentan las definiciones de la enfermedad, las causas u orígenes, los síntomas y los tipos de personas con problemas de alcohol. Hemos puesto de relieve la riqueza de las representaciones e ideas del personal biomédico y social en dicho dispositivo durante el trabajo etnográfico.

Los profesionales tienen conocimientos amplios de las personas con problemas de alcohol y otras drogas, pero para evitar procesos de "etiquetamiento" prefieren no señalarlos como "alcohólicos", sino que se refieren a ellos como personas con problemas de alcohol (pcpa). Sin embargo, en sus conversaciones cotidianas se colaban algunas designaciones prefiguradas y cuestionadas en el ámbito más "formal" como "el/la alcohólico/a", "el de alcohol", "el de coca"... Algunos psicoterapeutas apuntan diferencias sustanciales en cuanto a los drogodependientes según las sustancias que consumen, a pesar de sus muchos puntos en común interpretados a partir de la terapia sistémica relacional, que señala:

[...] [es] el síntoma que expresa una disfunción relacional entre el sujeto que bebe y el resto de los miembros de la familia permaneciendo en el tiempo, precisamente porque cumple una función que mantiene el equilibrio familiar (Cunillera i Forns, 2006: 31).

Desde el enfoque sistémico-relacional, otra de las profesionales llega a la siguiente definición: 
Para mí, es una persona..., no me gusta cronificar las cosas, hay personas que necesitan mucho más tiempo que otras para mejorar, ¿̇no?... Hay personas que durante determinados momentos de su vida que las cosas no acaban de funcionar bien y no acaban de encontrar la manera de salir de allí, lo que hacen es consumir..., no tanto que el problema está en la botella, ¿no?, sino que el problema para mí está en qué le pasa a esa persona que tiene que beber... (doctora Laia, 2009).

En los profesionales hay convergencia de planteamientos al poner en entredicho la idea que avala un "[...] discurso este de alcohólico para toda la vida, ¡ todo esto!... Prefiero hablar de personas, de personas que tienen determinados problemas en momentos de su vida y las acompaño para que puedan estar mejor" (doctora Laia, 2009). La persona a la que se la etiqueta como "alcohólico" se instala en ese estado de permanencia, es decir, es "alcohólico para toda la vida" y no produce ningún cambio en su vida.

Una de las profesionales señala que desde hace dos años atiende a pcpa, porque lleva más tiempo atendiendo a "heroína y coca", y señala el cambio de su visión con respecto a las pcpa:

[...] el paciente de alcohol lo disfruto mucho porque me siento cómoda, pienso que es un paciente como muy agradecido también. El de coca es más duro... Ahora hace dos años te hubiese dicho que con los de alcohol, "noooo". Ahora no te sé decir con quién me quedo, es que son gente que sufre mucho $y$ en silencio, que traga, traga y traga y no puede explotar, personalmente debe ser que me siento atraída a este tipo de gente (S. M., 2009).

En cuanto a los sentimientos que suele generar la relación terapeuta y usuario del CAS, señala una de las profesionales:

Hay pacientes que te generan también mucha "contradicción", los terapeutas también tenemos sentimientos. $Y$ aunque estamos acostumbrados a manejar nuestros propios sentimientos y a procurar que no perturben las dinámicas de las terapias, una persona te cae mejor que otra, es evidente. El recelo puede ser mutuo; si te miran con recelo, tú acabarás mirando con recelo. Una desconfianza dificulta la comunicación... (doctora Batalla, 2009).

A pesar del intento de no etiquetar y de no tener sentimientos contradictorios con respecto a las personas con problemas de drogas, también surgen 
concepciones sobre un tipo de paciente que se designa como "barracuda"; ${ }^{4}$ estas denominaciones se quedan en el interior de la institución para uso de los profesionales en el análisis de los casos y no son compartidas con los usuarios. Según nuestro criterio, dichas ideas nos informan sobre la trayectoria y experiencia de los profesionales desde una perspectiva más sociocultural que biomédica. Veamos su planteamiento:

Este es el tipo de personas que han hecho muchos tratamientos y en todos fracasan; nosotros le llamamos "barracuda", que es un pescado. Son pacientes "barracuda" que van quemando recursos, que van probando todo y confirmando que nada les sirve. Llegan aquí también a quemar este recurso para confirmar que nada funciona y que la culpa está fuera de ellos. No asumen ninguna responsabilidad. Vienen a ver qué encuentran, pero para confirmar que no hay nada, es la expectativa del no cambio (R. P., 2009).

Este tipo de persona va agotando los recursos, en su trayectoria de atención también ha pasado por Alcohólicos Anónimos y comunidades terapéuticas, ha hecho ingresos en hospitales, ha sido tratado ambulatoriamente por psiquiatras y psicólogos y "nada les sirve". Esta es la construcción sobre él y muchas veces de su familia, al constatar que lo que le ofrece la institución y los profesionales "tampoco le sirve"; así pues, "ya van con esta predisposición al fracaso" (R. P., 2009). Con las personas percibidas como "barracudas" según los terapeutas se plantea difícil el trabajo de psicoterapia.

\section{El arte de hacer "trajes a la medida": definiciones de los terapeutas sobre la enfermedad relacionada con el alcohol y otras drogas, síntomas y causas}

La definición de alcoholismo y/o "las personas con problemas de alcohol" (pcpa), los tipos de pcpa, las causas u orígenes y los síntomas, desde la perspectiva de los terapeutas, permiten dar cuenta de la complejidad de las narrativas relacionadas con estos aspectos. Todos los profesionales coinciden en la dificultad para definir el alcoholismo; tal como señala de manera jocosa una de las psiquiatras del centro, "el alcohol riega bien algunos terrenos" (doctora Martínez,

4. La designación surge del libro Pescando barracudas, de Joel S. Bergman (1999); el término barracuda es la metáfora que utiliza el autor para referirse a algunas familias resistentes al cambio que terminan quemando al terapeuta. 
2009). Es un término que todo el mundo da por entendido, pero cuando toca definirlo se dan muchas aproximaciones desde el lenguaje científico hasta el más popular; por eso se propone, a partir de Good (2003: 11), la consideración de que "la ciencia médica es en parte una formación ideológica". A partir de esta consideración, es imperioso realizar estudios socioculturales de los sistemas médicos que permitan a la antropología médica ocuparse no solo de las cuestiones referentes a biología y cultura, sino también "del sufrimiento humano, y de los rituales para afrontar los trastornos y peligros que puedan acechar a la persona, y, por lo tanto, de la investigación de la experiencia humana y de los cimientos existenciales de la cultura" (Good, 2003: 11); desde esta perspectiva se abordan los discursos tanto del profesional sanitario como de las pcpa.

Hay definiciones que identifican el malestar y el sufrimiento como factores explicativos en el mantenimiento de la situación de las"personas con problemas de alcohol"; su padecimiento se explica como un "síntoma que evidencia un conflicto interno o algún otro tipo de problemas". En este sentido, los profesionales señalan: "[...] son personas que tienen problemas con el alcohol, pero detrás hay una problemática social, económica, familiar que causa sufrimiento, malestar, algo..., que para poder soportar el dolor, el sufrimiento, empieza con los consumos que no son dañinos y los va incrementando" (Miguelina G., 2009). Así pues, debajo de la sustancia subyacen toda una serie de problemáticas que afectan a la persona y hacen que se refugie en la sustancia, pues:

[...] para mí, los problemas con el alcohol son síntomas del malestar. Y el malestar puede ser debido a muchísimas causas. El malestar asume muchas veces el síntoma de una disfunción familiar. La hipótesis que siempre nos hacemos los psicoterapeutas es: ¿qué ha podido pasar en esta familia para que una persona se encuentre tan mal y beba? Porque a veces es incluso una cuestión generacional. Desde los abuelos se ha ido transmitiendo un "mensaje", muchas veces inconsciente, que puede llegar a la persona afectada... (doctora Batalla, 2009).

$\mathrm{Su}$ interpretación permite articular al individuo con la sustancia y el contexto, que es lo que puede situar la problemática subyacente, que será diferente para cada caso. La enfermedad de las "personas con problemas de alcohol" es planteada por todos los profesionales desde una perspectiva de "diagnóstico a partir del consumo: como trastorno de abuso o de dependencia" (doctora Ba- 
talla, 2009). Dicha enfermedad “[... ] se manifiesta con una conducta, una conducta que suele aparecer en forma de dependencia o en forma de abuso cuando la persona está haciendo un mal uso que comporta un riesgo para la salud y que puede repercutir a nivel sociofamiliar" (doctora Muralla, 2009).

El planteamiento de los profesionales médicos se perfila hacia la definición de alcoholismo y la estigmatización de las personas:

[...] seguramente no voy por la parte más científica..., digamos que a nivel de valoración del alcoholismo es cuando se plantea que hay una dependencia directa al alcohol, pero que muchas veces no hace falta que haya una dependencia física como se describe en los manuales DSM-IV, 5 por ejemplo, ¿no?, o en el CIE- $10{ }^{6}$ Yo diría que es mucho más amplio, que toda aquella persona que comporte o tenga problemas relacionados con el consumo de alcohol, independientemente de la cantidad o que sea una dependencia, por el solo hecho de tener problemas ya lo podíamos plantear, el alcoholismo. Pero, al mismo tiempo, a veces no me gusta hablar de alcoholismo porque genera una etiqueta con una estigmatización que a veces no es conveniente, pero, bueno, nos entendemos cuando hablamos de alcoholismo, tenemos que usar un lenguaje común de todos modos (doctora Tecla, 2009).

La palabra alcoholismo genera una etiqueta estigmatizadora; por lo tanto, en los abordajes se procura cambiar el discurso de la persona, que se refiere a sí misma como "alcohólico/a" y que acude por ese problema, se llama por su nombre. Explica una profesional: "Cuando tratamos a cada individuo intentamos individualizarlo en cierto modo, y si vienen personas con una gran etiqueta o estigmatización, intentamos cambiarla, ¿no? Porque a veces le da identidad que tampoco es conveniente" (doctora Tecla, 2009). Desde un punto de vista psicoterapéutico se analiza "más como un síntoma que como una enfermedad en sí", pues lo interesante es "reconocer los problemas que hay debajo de ese problema de alcohol” (doctor Renato, 2009).

Las causas u orígenes del padecimiento de las personas con problemas de alcohol son muy diversos; desde el enfoque sistémico-relacional las causas son siempre sociales, ambientales, familiares o genéticas, pero no de manera determinante:

5. Manual diagnóstico y estadístico de los trastornos mentales DSM-IV de la American Psychiatric Association. 6. Es el acrónimo de Clasificación Internacional de Enfermedades, décima versión (versión en español). 
Son varias. Si pensáramos que fuese genético, yo pienso que representaría que nunca se va a arreglar. Yo siempre digo a saber hasta dónde llega la genética y dónde empieza el ambiente familiar. Puede que una persona tenga una base genética que la puede predisponer, pero el desencadenante es el ambiente en el que tú vives. En definitiva, los factores pueden ser genéticos, psicológicos, psiquiátricos, ambiente familiar y luego los individuales de cada persona. De hecho, hay muchos trastornos de personalidad que beben (doctora Muralla, 2009).

Las causas, aunque sean miles, desde esta perspectiva siempre tendrán que ver con lo familiar y relacional, cuyo factor siempre será de riesgo porque impedirá ver las cosas claras. La manera de evadirse del problema a nivel familiar ha sido esconderse tras una sustancia y no expresar ni resolver el malestar. También señala la psicoterapeuta que hay diferencias por género y que pueden ser múltiples, "de mil colores","no hay una causa que se repita en todos","las causas pueden ser miles", pero lo común suelen ser las "historias detrás de malestar en las familias".

El tema de la vergüenza es común a ambos, hombre y mujer: "Eso lo encuentras en todos lados", según la profesional de la salud, es decir, según su experiencia, va más allá del género. Una terapeuta destaca que "el tema de la vergüenza y esconderse en la mujer está como más presente". Es como si la mujer "tuviera más capacidad de disimular que todo está bien. Pero, bueno, tampoco quiero generalizar, ¡eh!” (doctora Laia, 2009).

La misma psicoterapeuta señala causas más sociales en el sufrimiento de las personas con problemas de alcohol, pues vivimos en una sociedad que "no enseña que cuando uno está mal", que cuando alguien se muere," no hay que llorar, que no es que vas a llorar toda la vida, pero cuando alguien se muere hay que expresar si estás triste", como si se considerara que si alguien se muere "no tienes por qué ponerte triste..., te puedes poner triste, ya dejarás de estarlo". También las convenciones sociales "imponen el estar bien y no dejamos que las cosas sucedan, estamos mal y luego gracias a eso podemos volver a estar bien". Se presenta la no expresión, la negación "como si las cosas negativas las tuviéramos que borrar". Así, "mientras más tapamos una cosa, más sale, ¿no?”. Como resultado, los pacientes no saben canalizar las emociones: "Si no puedes expresar el enfado, entonces lo vas a expresar de otra manera, ¿no?” (doctora Laia, 2009). 
Una psicoterapeuta destaca la autoatención de las personas que tienen problemas relacionados con las drogas, pues en los problemas relacionales que presentan suelen acudir al alcohol $\mathrm{u}$ a otra droga como "sustancia autotratamiento":

Aquí decimos que el consumo de la sustancia es un poco la punta del iceberg, la medicación es el alcohol o la sustancia que genera problemas, pero que, en definitiva, el problema de base acostumbra a ser otro, ¿no?, generalmente relacional, de dificultades relacionales y procesos psiquiátricos de base a veces, pero no necesariamente. Y que el alcohol está como sustancia autotratamiento, ¿no?, por decirlo de algún modo (doctora Tecla, 2009).

Otra de las causas ha sido asertivamente definida por una de las psicoterapeutas, quien lo denomina el "alcoholismo por ostracismo"; el negarse como persona hace necesaria la sustancia para relacionarse y para enfrentarse a los problemas o para escapar de ellos:

[...] [las causas] es que pueden ser, $i$ pufff!, muchas, desde un niño muy exigido a ser un marido que no tiene ni voz ni voto, a tener mucho estrés y necesitar desconectar, a ser una persona tímida que necesita beber para poder relacionarse y se le ha ido de las manos, a no querer implicarse en nada y si quiero me desconecto; hay muchas causas (doctora Valeria, 2009).

No hay que negar el mismo sufrimiento del paciente como una de las causas, tal como lo señala una de las trabajadoras sociales: "No sabría definirlo..., sufrimiento, insatisfacción, decepcionado, estrés postraumático" (Miguelina G., 2009). Sobre este punto se alegan causas genéticas, pero sin mucha certeza. Lo interesante es que es una de las educadoras sociales la que hace referencia a estas causas, lo que hace más interesante su puesta en escena porque refleja un discurso menos orientado desde el modelo sistémico:

[... ] bueno, no sé si es cierto, pero pienso que es un poco genético también, pero esto me lo estoy sacando un poco del bolsillo, supongo que hay personas que tienen más predisposición que otras, a lo mejor también más que genético es un patrón también, padres, abuelos, historias familiares ya de alcohólicos de cuarta generación... (Topacio M., 2009).

A pesar de los esfuerzos por dar una explicación desde la perspectiva sistémica relacional, se entretejen discursos tendentes a la generalización, a pesar del rechazo a hacerlo. En este sentido, cabe destacar la siguiente afirmación: 
Ah, es que depende, ¿no?, cada caso, cadascú és cadascú, cada caso es diferente..., es gente que desde jovencito ha empezado a beber, no sé, que la familia tenía ya tales bebedores, que es algo habitual o pues estos señores que se han separado de sus mujeres, que están solos, que se lo pasan el día en el bar y al final van perdiendo muchas cosas, que se han quedado sin trabajo, que tienen mucho tiempo libre, que no lo ocupan en ninguna otra cosa que no sea el consumo (Esmeralda S., 2009).

Todos los discursos tienden a buscar las causas u orígenes en "una disfunción en el entorno familiar y social" (doctora Batalla, 2009). Una perspectiva diferente de las ya propuestas es la ligada a lo lúdico y a las fiestas, es el gran "quitapenas", "aliviador de penas","refugio":

Aquí en España hay un consumo histórico y folklórico del alcohol, cuando hay fiesta familiar o tradicional va muy ligada al consumo de alcohol, ya desde las instituciones que lo permiten e incluso a veces lo promocionan. Hasta sirve de refugio a nivel social, para salir con los amigos o mucha gente lo utiliza para aliviarse las penas. ¿El origen, me preguntas? Folklórico, familiar, social y de evasión (Sergi E., 2009).

Hablar de causas fue complicado para los profesionales; una de las enfermeras señalaba: "Sería lo mismo preguntar: ¿por qué las personas padecen? Los motivos son muchísimos y dependen a la vez de cómo sea la persona" (Remei M., 2009). Otra de las reflexiones la ofrece una de las psicoterapeutas: "A ver, ¿es causa o consecuencia? No sabes qué es primero el huevo o la gallina: ¿bebes para olvidar u olvidas porque bebes?”. Pero hay una conexión con el contexto de la persona que "sustenta al problema desde sus inicios o de forma posterior lo está manteniendo". Cabe preguntarse entonces: “El entorno es un factor de inicio o un factor de mantenimiento?". La causa será muchas veces familiar, social o biológica (doctora Batalla, 2009).

Los síntomas de las pcpa se presentan cuando se hacen dependientes y su vida gira alrededor de la sustancia; cuando dejan de hacer cosas importantes para poder abastecerse, ingerir y estar "colocada", tal como señala el siguiente discurso:

Cuando ves a una persona que quiere dejar de beber y no puede. Yo siempre les digo que no depende tanto de personas que beben cada día y no tienen

7. Expresión en catalán; en castellano se traduce por “cada uno es cada cual”. 
ningún problema y que cuando quieren no beben. Hay personas que beben los fines de semana pero no tienen problemas [...], el problema es cuando uno quiere parar y no puede... Es cuando el alcohol empieza a ocupar mucho tiempo, vale, que a veces pasa cada día como te explicaba antes y a veces pasa pues solamente los fines de semana. Que la decisión sería que uno no puede parar y no estamos hablando de un consumo que uno haga cenando, comiendo (doctora Laia, 2009).

El síntoma básico es el malestar con uno mismo, la persona "se siente mal, nerviosa, porque es rechazada, no se siente bien consigo mismo ni con la sociedad, con los que conoce" (Abir, 2009). Otros síntomas tienen que ver con la pérdida de control de sí mismo en las relaciones con los otros: "Empiezan a faltar al trabajo, a que en la familia la relación es cada vez más negativa, a que la pareja cada vez está más cansada, no aguanta más, un distanciamiento, estar bebiendo y llegar a casa a dormir, a no hablar, no comentar, tiene que esconder lo que ha bebido, a engañar". Otro de los síntomas "es que engañan, pero se ve enseguida; a negar lo evidente. Son síntomas que te permiten darte cuenta de que la persona tiene problemas en el trabajo, llegar tarde, por el cansancio". Cuenta también la edad, según la psicoterapeuta, pues"no es lo mismo la resaca de 25 años que una resaca a los 40. Cada día cuesta trabajar y cumplir, a los 40 ya una resaca cuesta más, pierde el trabajo y eso genera una problemática mayor" (doctora Valeria, 2009).

Hay también síntomas físicos y síntomas relacionales según la trabajadora social; los primeros hacen referencia al "síndrome de abstinencia" y los segundos son verbalizados cuando "le dice al especialista para dejar de beber, pero no es solo eso, detrás hay toda una problemática, problemas judiciales, el ambiente de casa es muy malo" (Miguelina G., 2009).

Entretanto, las educadoras sociales refieren los síntomas más físicos: “ $¡ H o m-$ bre!, claro que los manifiestan: dificultad en los movimientos, en el hablar, en la falta de coordinación, a lo mejor incluso en la respiración, estar más acalorados, incluso yo que sé, depende de la persona puede estar más agresiva”. Cuando acuden al recurso dispuesto como centro de calor y café, el comentario más común por parte de los monitores y educadores suele ser: “ $\mathrm{Oh}$, ¿pero cómo vienes así?» «No, solo me he bebido una cerveza». Pero esa una cerveza son a lo mejor tres cervezas". Considera que "tienden a minimizar su propio problema cuando ellos saben perfectamente que beberse tres cervezas a las nueve de la 
mañana quizás es una barbaridad" (Topacio M., 2009). Es reiterativo lo del síndrome de abstinencia en el discurso de las educadoras y los trabajadores sociales; como síntoma se circunscriben a lo físico y en algunos casos a lo emocional: "Necesitar beber por la mañana si no tienes delirios, temblores, malestar, ¿no?, o el necesitar o asociar cada vez que hay problemas con la bebida, pues esto es también un síntoma, ¿no?, no saber gestionarte emocionalmente" (Esmeralda S., 2009). Existen explicaciones de los psicoterapeutas circunscritas a los síntomas físicos y biomédicos: "Como médico te diría las arañas vasculares, el enrojecimiento de piel, el color es muy característico, las hepatitis, cirrosis..." (doctora Norma, 2009).

Un síntoma común es la depresión, puesto que "casi siempre detrás de una persona con problemas de alcohol hay una persona deprimida" (doctora Norma, 2009). Esto sugiere la posibilidad de repensar, a partir de los discursos de los pacientes, el "sufrimiento social" de las pcpa. Al respecto, Scheper-Hughes (1997: 184) señala que "la estructura de los sentimientos individuales y colectivos y la percepción del cuerpo personal se da en función de la posición y el papel que se juega en el orden técnico y productivo". Así pues, las tácticas mentales/corporales de los "otros" son etiquetadas como "desviantes, patológicas, irracionales o inadecuadas". Scheper-Hughes, a partir de Kleinman, explica la función de las "somatizaciones" como "un mecanismo de defensa por lo general mal adaptado y bastante primitivo que implica la utilización del cuerpo en la producción o exageración de síntomas como una forma de expresar sentimientos negativos u hostiles". Es así como el tipo de "alcoholismo depresivo" formulado por los terapeutas se repite constantemente no solo a partir del personal sanitario, sino también de los "pacientes". En la sintomatología expuesta es interesante ver la manera como culturalmente transmiten al terapeuta los síntomas relacionados con su problemática existencial:

[...] depresión la mayoría, depresión, ansiedad asociada a la depresión y muchos somatizan, psicosomatizaciones, ¿no? “Tengo un nudo aquî", "es que tengo un peso aquí,"'me duele aquí," "noto unos dolores"...; muchas somatizaciones "me duele la tripa", "es que tengo unos ahogos", y te das cuenta de que están somatizando la ansiedad del malestar que tienen..., una consecuencia de la depresión es el aislarse, el costar abrirse... Muchas veces no está reconocida esta depresión (doctora Batalla, 2009). 
Los terapeutas, como actores sociales, nos ofrecen un abordaje de las drogodependencias desde el enfoque sistémico-relacional, las definiciones de la enfermedad, las causas u orígenes, los síntomas y los tipos de personas con problemas de alcohol. Hemos puesto de relieve la riqueza de los discursos y las experiencias del personal biomédico y social en dicho dispositivo durante el trabajo etnográfico.

\section{La elaboración de "trajes a la medida": abordaje psicoterapéutico de los profesionales del CAS}

La metáfora del "traje a la medida" concibe que cada persona es un mundo; precisamente, "el trabajo psicoterapéutico es como bastante artístico, es muy creativo" (doctora Batalla, 2009). Los terapeutas poseen una serie de conceptos más o menos generales, pero luego con cada persona tienen que crear pautas, tratamientos particulares, "trajes a la medida", para ver cómo se adecuan a la realidad de la persona y cómo se crea un vínculo entre el usuario y el terapeuta. Es decir, de qué manera se pueden ir definiendo o redefiniendo los problemas que tiene. Los terapeutas consideran que "cada persona tiene sus razones de ser y es diferente". Con cada persona tienen un trato diferenciado dependiendo de si hay un buen vínculo o una relación terapéutica establecida. Y luego está presente "el propio estilo del terapeuta, que a veces choca con el estilo del paciente" (doctora Batalla, 2009). Lo contrapuesto a esto sería la "transferencia" que se da entre las personas, la empatía.

La creación del "traje a la medida" se realiza mediante la asistencia al usuario y a la familia. Para ello, el terapeuta debe seguir una serie de pasos. En primer lugar, una vez que el usuario y/o la familia acude al servicio por iniciativa propia o derivada por diferentes instituciones, sostiene una entrevista con el/ la trabajadora social, se analiza la demanda y se informa de la situación familiar, sanitaria, psicológica, penal..., del usuario. Ello permite llevar a cabo una evaluación y plantear los recursos disponibles adecuados a las circunstancias del usuario y al tipo de tratamiento que se realizará en el servicio. Es lo que algunos terapeutas llaman, en lugar de "traje a la medida", "menú del día", pues se ajusta a las necesidades de cada individuo. El circuito de atención a los usuarios tiene una perspectiva integral (abordaje biopsicosocial); además de tratar el consumo, en el proceso terapéutico se acompaña al usuario teniendo en 
cuenta la salud, el bienestar interno y el entorno cercano. Gracias a un equipo interdisciplinario, se trabaja con la persona "dependiendo de las necesidades del individuo que se trata" (Miguelina G., 2009).

Este encaje inicial entre usuario y terapeuta surge a partir de "relaciones humanas que se van produciendo..., son relaciones terapéuticas". Estas relaciones terapeutas se tejen de manera compleja e "intuitiva". $\mathrm{Al}$ respecto:

No creo que lo deseable sea que todo tienda a la evidencia científica, que todo tenga que tener una evidencia científica en sentido estricto para saber si es eficaz. En psicología es muy difícil y en relaciones humanas. De todas maneras pienso que se ha de evaluar más, cualitativa más que cuantitativamente; no se pueden aplicar los mismos parámetros médicos y biológicos a las ciencias sociales, a las ciencias humanas, hay que buscar otros parámetros (doctora Batalla, 2009).

El tratamiento como "traje a la medida" defiende para "cada persona un tratamiento según lo requiera”. Tendrá entonces un proceso terapéutico en el cual estará guiada por los terapeutas o referentes (psicoterapia, enfermería, educación social, inserción laboral). Se identifican sus problemas y se decidirá su pauta médica, psicoterapéutica o social. Se adapta y diversifica según cada persona.

Desde la perspectiva sistémico-relacional, una profesional señala lo que es la psicoterapia:

La psicoterapia permite hacer unas hipótesis de qué es lo que le está pudiendo pasar a esta persona, por qué ha llegado a este punto. Y permitir que se explique y cuente lo que le pasa y el terapeuta saber ir ordenando esa información y resituarla para elaborarse una hipótesis de lo que le pueda estar pasando. A veces resituar el pasado pero con ánimos de situarnos en el presente y con la intención de mejorar el futuro, un poco a grosso modo esto sería un proceso terapéutico (doctora Batalla, 2009).

Los profesionales describen en detalle el proceso terapéutico, aportando incluso las técnicas y los rituales que utilizan desde la perspectiva sistémicorelacional. En tal sentido, el doctor Renato señala que la primera visita con la persona "es como una metáfora de todo el proceso terapéutico"; esto quiere decir que, según como se desenvuelva la primera visita, marcará todo lo que vendrá después. Así pues, es importante crear un consenso con la persona y for- 
mular una "especie de proyecto o plan de lo que se va a hacer en ese caso concreto"; para ello es indispensable "un buen clima", "buen rollo," "trabajar la empatía".

Estas primeras interpretaciones son fuente de explicaciones o metáforas que dan lugar a una hipótesis "que tenga sentido para el terapeuta y sobre todo para el paciente" y que permita en el proceso terapéutico hacer los cambios para transformar la realidad de la persona. Lograr esta comprensión no es fácil, pero, por lo menos, sirve para elaborar una interpretación que le da un nuevo sentido a las creencias y los comportamientos de las personas en un momento dado. Según este profesional, "un buen indicador de si la sesión de psicoterapia está marchando bien o mal es que el paciente hable más que el terapeuta; cuando el terapeuta habla más que el paciente, es que va muy mal [se ríe]. Se está haciendo terapia el propio terapeuta" (doctor Renato, 2009).

La mayoría de los profesionales opinan que es posible la "curación" o "recuperación" de la persona con problemas de alcohol, pero esta curación es relativa en todos los planteamientos, pues depende de si se entiende "que curarse es no beber". Sostienen que siempre habrá más cosas que curar relacionadas con el alcohol —en este caso, las relaciones y el contexto de la persona-; implica la influencia de "factores sociales, conflictos familiares, enfermedades orgánicas" y la verdadera intención del actor social, que no es "paciente" sino "actuante" (doctor Renato, 2009).

\section{Conclusiones}

Podemos afirmar que el conjunto de representaciones y prácticas de los profesionales es diverso y heterogéneo, por lo que se consideró importante su interpretación. La larga trayectoria de los profesionales en el CAS ha permitido recoger sus narrativas y experiencias acerca de la definición de la enfermedad, los síntomas y las causas, así como la práctica de elaborar el tratamiento como un "traje a la medida", entre otros aspectos.

Al centrarnos en un centro de atención y seguimiento de las drogodependencias, hemos podido ver las representaciones de los terapeutas en un marco de tipo biomédico que, no obstante, tiene sus propias formas organizativas y un conjunto de creencias y prácticas manejadas desde el enfoque sistémicorelacional. Lo anterior redefine la creación de un sector profesional, el de la intervención en el campo de las drogodependencias, compuesto por profesio- 
nales del área de la salud y de las ciencias sociales, que se configurará a partir del modelo que domina el campo asistencial de las drogas: el biopsicosocial.

En el trabajo se retoma la metáfora del "traje a la medida", según la cual el terapeuta (sastre) elabora (confecciona) tratamientos (traje a la medida) para las personas con problemas de alcohol u otras drogas. Las ideas relacionadas con el "traje a la medida" me parecieron inspiradoras para analizar el abordaje del tratamiento de las drogas desde la perspectiva de los profesionales. Desde la perspectiva del enfoque sistémico-relacional, los terapeutas analizan (o hilvanan) en la práctica el mundo de las personas con problemas de alcohol en el contexto cambiante del Servicio de Drogodependencias. El terapeuta inicia el tratamiento con la persona y entabla una relación de confianza para indagar su problemática y hacer que deje los consumos abusivos de la sustancia (es decir, la incentiva a reducir el consumo y/o abandonarlo con medicación) al igual que el sastre corta la tela y cose sus trajes según es necesario sobre la base de su experiencia. Si la tela se ha cortado bien (tras identificar la enfermedad, los síntomas y las causas), el traje será bueno y útil; si se ha cortado mal, no le quedará bien al que lo debe usar. De igual manera, el terapeuta despliega sus "artes terapéuticas". Si la confección del tratamiento se ha planteado bien, la persona saldrá adelante con sus propios recursos y los facilitados por el dispositivo donde laboran los terapeutas; si se ha confeccionado mal, la persona no avanzará hacia su "curación".

Habría que tener en cuenta también la posible combinación de ciertos tratamientos para el usuario, su valoración acerca de lo que considera un "buen tratamiento" - decidido con él—, para que de este modo el tratamiento pueda tener una mayor eficacia real; también por una cuestión de eficacia simbólica. El "traje a la medida" supone que a cada persona le corresponde un tratamiento según lo que requiera. Es, por lo tanto, una rica metáfora que habla de una diversidad de opciones según la persona, la sustancia y el contexto, y en cuyo estudio valdría la pena profundizar. 


\section{Bibliografía}

Bergman, Joel S. (1999) [1985]. Pescando barracudas. Barcelona: Paidós.

Bimbela Pedrola, José Luis (1995). Cuidando al cuidador. Counseling para profesionales de la Salud. Granada: Documentos Técnicos núm. 8, Escuela Andaluza de Salud Pública. Junta de Andalucía.

Cunillera i Forns, Carmen (1996). Personas con problemas de alcohol. La abstinencia no es suficiente. Barcelona: Paidós.

Good, Byron J. (2003). Medicina, racionalidad y experiencia. Una perspectiva antropológica. Barcelona: Edicions Bellaterra.

Menéndez, Eduardo y Renée Di Pardo (1996). De alcoholismos y algunos saberes. Atención primaria y proceso de alcoholización. México D.F.t CIESAS.

Menéndez, Eduardo L. (2002). La parte negada de la cultura. Relativismo, diferencias y racismo. Barcelona: Edicions Bellaterra.

Parsons, T. (1999). "Estructura social y proceso dinámico: el caso de la práctica médica moderna”. El sistema social. Madrid: Alianza Editorial.

Romaní, Oriol (1999). Las drogas. Sueños y razones. Barcelona: Ariel.

Scheper-Hughes, N. (1997). La muerte sin llanto. Violencia y vida cotidiana en Brasil. Barcelona: Ariel.

White, M. (2002). El enfoque narrativo en la experiencia de los terapeutas. Barcelona: Editorial Gedisa. 